\title{
Remarks by World Bank Group President David Malpass to the Nordic and Baltic Ministers and Governors of the World Bank Group
}

June 1, 2021

Thank you Minister Saarikko and Minister Skinnari for hosting this meeting with Nordic and Baltic ministers and Governors of the World Bank Group. I am very pleased that my first destination after over a year without mission travel is to the Nordic region. This constituency is consistently one of the Bank Group's most dedicated and ambitious groups.

The last time I was in this part of the world was in December 2019 for the IDA19 replenishment meeting in Stockholm. With the help of forward leaning donors like the Nordic and Baltic countries, we mobilized a historic $\$ 82$ billion financing package. We didn't know then how important that record replenishment would be. As you know, we shortened the IDA19 implementation period by a year after frontloading IDA's resources to help countries recover from the pandemic.

I had the pleasure to meet most of you virtually around this time last year. I recall a lively discussion on many important topics, ranging from the immediate health impact of COVID-19 to the long-term effect of climate change. Before getting back to these issues, I would like to set the stage regarding the extent of the global crisis, and the depth of its consequences. I will then focus my remarks on the financing needs in lowincome countries, vaccines, climate change and debt.

Let me also just make sure that I introduce Jakob Kopperud, who is joining us virtually. Many of you will know him from his previous World Bank roles, and I'm happy to welcome him here today on his first day in his new role as our Special Representative to Europe. Welcome Jakob.

Since the beginning of the pandemic, over 100 million people were pushed into extreme poverty, with an additional 50 million expected by the end of 2021. Around 250 million jobs have been lost, and an additional 130 million people face chronic hunger and malnutrition because of the economic impacts of COVID-19, effectively doubling the number to over 270 million.

Beyond the immediate impact, the crisis has increased inequality in much of the world. COVID-19 is widening gender gaps, reversing decades of gains for women and girls in areas like education, economic empowerment, and female agency. Global food prices rose by 20 percent between January 2020 and January 2021; over 60 percent of households reported reduction in total income; and 1.6 billion children were out of school, resulting in more than half a year of learning losses.

The pandemic has also highlighted the consequences of several slow-burning crises rising conflict and violence, displacement, stagnant median incomes, collapsed businesses and lost jobs, the depletion of savings and assets, loss of agency for women, and damage caused by climate change. 
In response, the World Bank Group mounted the fastest and largest crisis response in its history. In 2020, the World Bank achieved a record 65 percent growth in commitments. Group-wide commitments topped $\$ 100$ billion for the first time, reaching $\$ 108$ billion. We also saw a significant increase in the speed and volume of our disbursements, with over $\$ 50$ billion dollars in cumulative disbursements between March 2020 and April 2021. We expect this elevated level of delivery to continue in 2021.

What these disbursements mean is that we're getting finances to people in need and using all available platforms to reach the poorest. We scaled up our cash transfer programs, which provide rapid and direct relief to the poor, vulnerable, and most marginalized groups, including women, the disabled, unemployed youth, and the elderly. From March 2020 until April 2021, we have committed over $\$ 6.3$ billion in direct financing of cash transfers programs, across 22 countries benefitting over 130 million poor people. We want to build on this knowledge and further invest in enhancements to social registries to improve the coverage of the poor and enhance digital payments to facilitate rapid, safe, and secure delivery of income support.

On vaccines, we have been pleased to see the rapid development of safe vaccines and their deployment in some poor countries, but we are deeply concerned about the limited and uneven access around the world. As I said in my recent op-ed, a successful global vaccination effort must stand on three pillars. First, countries with an adequate vaccine supply should immediately release doses to countries that have deployment programs. Second, we need to distinguish between contracts and options versus "understandings" between governments, pharmaceutical companies, and organizations involved in vaccine production and delivery so that financing can be directed effectively, and countries can plan for receipt and deployment. This is also critical to enable the private-sector investments that will be needed to expand supply. And third, we need to increase vaccine production.

Geir and his colleagues on our Board have already approved financing now available in 22 developing countries, with several dozen more expected by mid-year under the fasttrack process we used for emergency COVID-19 assistance in 2020. This financing can pay for vaccine purchases and shipments if needed and facilitate rapid vaccine deployment through national health systems, including vaccines from

COVAX. Standardized, transparent contracts that arrange for fair and equitable distribution are crucial.

On vaccine transparency, the World Bank launched a comprehensive online portal in late May that provides easy access to information about our projects, including individual country-financing operations; and the vaccine-readiness assessments in over 140 low and middle-income countries, undertaken together with WHO, UNICEF, the Global Fund, and Gavi.

On vaccine production, IFC has invested over $\$ 800$ million dollars in health care, including in vaccine manufacturers. And it currently has another $\$ 1.2$ billion dollars in the pipeline through the Global Health Platform, a $\$ 4$ billion dollars financing mechanism created to help meet the immediate need for vaccines, medical equipment, and health services. As was discussed last week with our Board, an IFC-led consortium is working to expand vaccine production capacity for developing countries. 
COVID-19 has made us rethink how we approach pandemic preparedness. IFIs can build on their pandemic response financing to lay the foundations for country preparedness and resilience to future crises. IDA does that by prioritizing preparedness investments and health systems strengthening and embeds these efforts into core country operations. IDA also enables earlier responses to slow-onset crises, such as disease outbreaks, drought, and food insecurity.

Let me then turn to climate change, one of the defining trials of this century. I had the pleasure of meeting Minister Fridh recently, where we spoke about the challenges caused by climate change.

To deliver on our twin goals of reducing poverty and boosting shared prosperity, it is critical that the World Bank Group supports our clients to unlock the benefits of green, resilient, and inclusive development -- or what we now call GRID. It is also important we help countries maximize the impact of climate finance, with measurable improvements in livelihoods through adaptation, and measurable reductions in greenhouse gas emissions through mitigation.

I was pleased to announce our alignment with the Paris Agreement in April. Under our new Climate Change Action Plan, the World Bank commits to align all new operations by 2023. IFC and MIGA will align $85 \%$ of new operations by 2023 and all new operations by 2025. 35 percent of WBG financing will have climate co-benefits, on average, over the next five years.

The Bank Group is already the biggest funder of climate investments in developing countries, with half going to climate adaptation. Between 2016 and 2020, the Bank Group delivered over $\$ 83$ billion dollars in climate finance. In 2020 alone, the Bank Group committed $\$ 21.4$ billion dollars in climate finance. And we are eager to do more.

As stated in our Climate Change Action Plan, we will produce our own dedicated country climate and development diagnostic, the new Country Climate and Development Report (CCDR), and will support the development and implementation of clients' NDCs for low-carbon and climate-resilient development, including carbon pricing, using a whole-of-economy approach.

We are committed to closing the energy access gap for the poorest, mainly by helping countries deliver access to affordable, reliable, and sustainable energy. From FY15-19, more than 90 percent of our total power generation lending went to renewables, far outpacing the global average of 65 percent renewable energy investments. As the generation from renewables increases, there will need to be added baseload capacity from a narrow group of low-carbon energy sources.

We consider biodiversity and ecosystem services a development issue in its own right. Nature-based solutions will play a key role in supporting mitigation and adaption, and we are committed to a more ambitious and comprehensive approach to nature.

I am pleased that this Group are all members of the Coalition of Finance Ministers for Climate Action, and that you subscribe to the Helsinki Principles. We will continue to promote national climate action, especially through fiscal policy, use of public finance, and increased borrower support for environmental and social safeguards. 
This is where international cooperation can help: striving for sound fiscal policy, transparency and use of public finances to lay the foundation for green, resilient, and inclusive development that benefit the most vulnerable and the most marginalized.

Finally, let me turn to the issue of debt. The World Bank Group is committed to comprehensive debt solutions that can bring real benefits to people in poor countries, particularly countries that don't have the financial resources to respond to the COVID-19 crisis. On the eve of the crisis, half of all IDA-eligible countries were already in debt distress or at high risk of it.

Comprehensive debt solutions will involve at least four elements—debt suspension, debt reduction, debt resolution, and debt transparency.

The G20's Debt Service Suspension Initiative (DSSI) has been a good first step in providing cash-flow relief to countries that need it most. As of mid-May, 47 countries are participating in the initiative. Between May 1, 2020 and the end of 2020, the DSSI delivered more than $\$ 5$ billion dollars in relief and is expected to deliver an additional $\$ 7.3$ billion dollars by the end of this month. However, the private sector didn't participate and participation by the public sector was incomplete, severely diminishing the effectiveness of the suspension.

A permanent solution is necessary to reduce the interest rates on and stock of external debt in the poorest countries. What is needed now is prompt implementation of the G20's Common Framework, which is designed to provide effective debt treatments for countries with unsustainable debt burdens. Full official creditor and private-sector participation is required for greater impact. A permanent solution will also require additional progress on two other fronts: debt transparency and the framework for sovereign debt restructuring.

Countries are increasingly taking on debt on non-concessional terms-from private lenders and governments that are not members of the Paris Club. The lack of participation of commercial creditors in the debt-relief efforts so far is reducing the effectiveness of the G20's efforts. As we move towards implementing the Common Framework, private creditors are required to participate on terms comparable to those of official bilateral creditors. Their participation is complicated yet critical for the success of the Common Framework.

This group of countries have a long history of supporting debt relief efforts. With the support of Norwegian bridge financing, Somalia normalized relations and reengaged with IFIs in 2020. Sudan has made pivotal progress on debt, along with the unification of the exchange rate, which proved to be immediately beneficial to the people of Sudan. We are now working together toward the HIPC Decision Point for Sudan in June, and I know I can count on your support here as well.

Our collective responses to climate change, poverty and inequality are defining choices of our generation. We have an opportunity to improve development outcomes for countries, reduce extreme poverty and address the dangers of inequality, social instability, and conflict, but it will require strong coordination, high ambition, and a continued global effort at scale. 
I will be speaking at the St. Petersburg Economic Forum this week on these topics. I was last in Helsinki and Leningrad in 1975, also a period of great economic and geopolitical challenge. Since then, Russia and its neighbors in Asia, eastern Europe, and the Arctic - and indeed people around the world - have changed profoundly. Most people are freer and more prosperous. Technology connects us and adds to our lives and awareness of others in ways we could never imagine.

Even as the recovery takes hold in some parts of the world, many of the world's poor still live without electricity or clean water. For them, the pandemic weakened the chances for advancement, creating lasting damage to their health and resulting in lost months and even years of vital education and skills development. The armed confrontations and disruptions to rule of law in several parts of the world are a major obstacle to development, and it is incumbent on all parties to find peaceful solutions.

I would be remiss not to mention the current situation in the West Bank and Gaza. As efforts turn to rebuilding, the World Bank has launched a Rapid Damage and Needs Assessment, jointly with the EU and the UN, and with strong ownership of the Palestinian Authority. Drawing on the Bank's experience of responding to the Beirut explosion in August 2020, the assessment is going to be genuinely rapid and is scheduled for completion by the end of June. A recovery plan will follow, and the Bank has already begun identifying opportunities for restructuring projects in the existing portfolio for Gaza emergency response. I took note of Norway's recent announcement that it is increasing its humanitarian aid to the Palestinian people by 30 million kroner. We would welcome this constituency's assistance via our trust funds to help rebuild and in order to avoid fragmentation.

I trust that our discussion today will bring us further in crafting an effective response to COVID-19. Your commitment to international cooperation across global fora speaks for itself, be it as Chair of the IMFC - Minister Andersson; co-chairing of the Coalition of Finance Ministers for Climate Action - Minister Saarikko; or co-chairing the ACT-A Facilitation Council - Minister Ulstein.

You are also longstanding supporters of IDA, and we are going to need your full support for the ongoing IDA20 Replenishment. As the world's poorest countries tackle the immediate and longer-term impacts of the pandemic, they will also need more support from IDA, on a sustained basis, through grants and highly concessional resources. More than half of active IDA countries already receive all, or half, of their IDA resources as grants, and this support is crucial to add to countries' fiscal space and boost their ability to respond to the crisis without adding to debt vulnerabilities.

I welcome your views and reflections on the year that has passed, how we can respond to the diverse and interconnected challenges, and how we can work toward a green, resilient and inclusive recovery.

Finally, I would like to thank Geir for his work on the World Bank Board in the past two years. His experience, tact and curiosity are an asset for the Board, Bank Group management and for me personally. I look forward to working with Lene Lind in her capacity as Executive Director starting July 1.

Thank you. 